Research Paper

\title{
Scavenger Receptor Class B Type I Gene rs5888 Single Nucleotide Polymorphism and the Risk of Coronary Artery Disease and Ischemic Stroke: A Case-Control Study
}

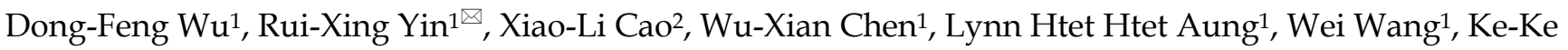
Huang1, Ping Huang ${ }^{1}$, Xiao-Na Zeng ${ }^{1}$, Jian $\mathrm{Wu}^{1}$

1. Department of Cardiology, Institute of Cardiovascular Diseases, the First Affiliated Hospital, Guangxi Medical University, 22 Shuangyong Road, Nanning 530021, Guangxi, People's Republic of China

2. Department of Neurology, the First Affiliated Hospital, Guangxi Medical University, 22 Shuangyong Road, Nanning 530021, Guangxi, People's Republic of China

$\triangle$ Corresponding author: Prof. Rui-Xing Yin, Department of Cardiology, Institute of Cardiovascular Diseases, the First Affiliated Hospital, Guangxi Medical University, 22 Shuangyong Road, Nanning 530021, Guangxi, People's Republic of China. Tel: +86-771-5326125; Fax: +86-771-5353342; E-mail: yinruixing@163.com

(1) Ivyspring International Publisher. This is an open-access article distributed under the terms of the Creative Commons License (http:/ / creativecommons.org/ licenses/by-nc-nd/3.0/). Reproduction is permitted for personal, noncommercial use, provided that the article is in whole, unmodified, and properly cited.

Received: 2013.06.29; Accepted: 2013.09.15; Published: 2013.10.16

\begin{abstract}
Background: Our previous studies have showed that the rs 5888 single nucleotide polymorphism (SNP) in Scavenger receptor class B type I (SCARBI) gene is associated with serum lipid levels in the general Chinese populations. The present study was undertaken to detect the associations between rs5888 SNP and the risk of coronary artery disease (CAD) and ischemic stroke (IS).

Methods: A total of I,7I6 unrelated subjects (CAD, 60I; IS, 533; and healthy controls, 582) were included in this study. Genotyping of the rs5888 SNP were determined by polymerase chain reaction and restriction fragment length polymorphism.

Results: The genotypic frequencies of SCARB I rs5888 SNP were different between CAD patients and controls, the subjects with TT genotype had high risk of CAD (OR $=1.76, P=0.038$ for TT vs. $C C$; and $O R=1.75, P=0.036$ for TT vs. $C C / C T$ ). There was no significant association between genotypes and the risk of IS. Further analysis showed that the subjects with TT genotype in the total population had lower levels of high-density lipoprotein cholesterol than the subjects with CC/CT genotypes $(P<0.05)$, the subjects with TT genotype in controls but not in CAD or IS patients had higher levels of serum LDL-C and ApoB than those with $C C$ genotype $(P<0.05$ for each).
\end{abstract}

Conclusions: The present study suggests that the SCARBI rs5888 SNP influences serum lipid levels, and is associated with the risk of CAD.

Key words: Scavenger receptor class B type 1 gene, Single nucleotide polymorphism, Coronary artery disease, Ischemic stroke, Lipid

\section{Introduction}

Among the non-communicable diseases, cardiovascular and circulatory diseases mainly comprising ischemic heart disease $(5.2 \%)$, hemorrhagic stroke $(2.5 \%)$, ischemic stroke (IS, $1.6 \%)$, and hypertensive heart disease $(0.6 \%)$, accounted for $11.8 \%$ of global DALYs (disability-adjusted life years) [1]. Both coronary artery disease (CAD) and IS shared the common risk factors such as hypertension, diabetes, 
dyslipidemia and metabolic syndrome [2], and the common pathophysiology mechanisms: atherosclerosis [3]. Dyslipidemia such as elevated serum levels of total cholesterol (TC), triglyceride (TG), low-density lipoprotein cholesterol (LDL-C), and apolipoprotein (Apo) B, or low levels of high-density lipoprotein cholesterol (HDL-C) and ApoAI is one of the most important modifiable risk factors for CAD $[4,5]$ and IS $[6,7]$. It is well known that the disorder of lipid metabolism is a complex trait resulted from multiple environmental and genetic factors and their interactions $[8,9]$.

The Scavenger receptor class B type 1 (SCARB1), also as known as $S R-B I$, is a HDL receptor which binds HDL-C with high affinity, mediates selective cholesterol uptake of HDL, and plays an important role in reverse cholesterol translation [10]. Previous studies have shown its importance in lipoprotein metabolism and atherosclerosis in mouse models. In targeted deletions of the murine $S R-B I$ gene, TC levels were significantly increased in homozygous $S R-B I-/-$ mice, and analysis of the lipoprotein profiles by fast protein liquid chromatography showed a significant increase in HDL-C levels and a shift of the HDL particles to a larger size $[11,12]$. Inversely, lower plasma levels and accelerated clearance of HDL and non-HDL-C were found in SCARB1 transgenic mice [13]. In LDL receptor-deficient mice, attenuated expression of SCARB1 was associated with increased LDL-C and accelerated atherosclerosis [14,15]. The association of several variants in the SCARB1 gene and serum lipid profiles has been reported in diverse populations [16-28]. One of the single nucleotide polymorphisms (SNPs) in the SCARB1 gene is rs5888 SNP, which was initially found by Acton [17], a "C" to " $\mathrm{T}$ " substitution at $\mathrm{CDNA}$ position 1050 base position on exon 8. The rs5888 SNP T allele has been associated with increased serum HDL-C levels and decreased risk of atherosclerosis related diseases [24-28]. In our previous studies, however, we found that the rs5888 SNP $\mathrm{T}$ allele was associated with decreased HDL-C levels and increased TC, LDL-C and ApoB levels in three Guangxi populations $[29,30]$. Therefore, the aim of the present study was to determine the associations between rs5888 SNP and the risk of CAD and IS in the Han Chinese.

\section{Materials and methods}

\section{Patients and controls}

A total of 601 patients with CAD were recruited from hospitalized patients in the First Affiliated Hospital, Guangxi Medical University. Coronary angiography was performed in all enrolled subjects. CAD was defined as significant coronary stenosis $(\geq 50 \%)$ in at least either one of the three main coronary arteries or their major branches (branch diameter $\geq 2 \mathrm{~mm}$ ). Subjects with congenital heart disease, cardiomyopathy, valvular disease, autoimmune disease and type I diabetes mellitus were excluded.

A total of 533 patients with IS were also recruited from hospitalized patients in our affiliated hospital. All patients received strict neurological examination and brain magnetic resonance imaging (MRI) scan. IS was diagnosed according to the International Classification of Diseases (9 ${ }^{\text {th }}$ Revision). The patients with transient ischemic attack (TIA), embolic brain infarction, stroke caused by inflammatory diseases, cardioembolic stroke, autoimmune disease, serious chronic diseases, as well as a past history of CAD have been excluded from the study.

A total of 582 healthy subjects matched by age, gender, and ethnic group (Han Chinese) were also recruited as a control group. The controls were judged to be free of CAD, IS and other diseases by questionnaires, history taking and clinical examination.

All enrolled individuals were Han Chinese from Guangxi, People's Republic of China. A standard questionnaire was used to ascertain the general information and medical history for all participants. The study protocol was approved by the Ethics Committee of the First Affiliated Hospital, Guangxi Medical University. Informed consent was obtained from all subjects after they received a full explanation of the study.

\section{Genotyping and biochemical analysis}

Venous blood sample was obtained from all subjects after at least 12 hours of fasting. Genomic deoxyribonucleic acid (DNA) was extracted from peripheral blood leukocytes using the phenol-chloroform method. Genotyping of the SCARB1 rs5888 SNP was performed by polymerase chain reaction and restriction fragment length polymorphism $[29,30]$. The levels of serum TC, TG, HDL-C, and LDL-C in samples were determined by enzymatic methods with commercially available kits. Serum ApoAI and ApoB levels were detected by the immunoturbidimetric immunoassay.

\section{Diagnostic criteria}

The normal values of serum TC, TG, HDL-C, LDL-C, ApoAI, ApoB levels, and the ratio of ApoAI to ApoB in our Clinical Science Experiment Center were 3.10-5.17, 0.56-1.70, 0.91-1.81，2.70-3.20 mmol/L, $1.00-1.78,0.63-1.14 \mathrm{~g} / \mathrm{L}$, and 1.00-2.50; respectively $[29,30]$. Hypertension was diagnosed according to the criteria of 1999 World Health Organization-International Society of Hypertension Guidelines for the management of hypertension [31]. Uncon- 
trolled hypertension was defined as a systolic blood pressure of $140 \mathrm{mmHg}$ or higher and a diastolic blood pressure of $90 \mathrm{mmHg}$ or higher. The subjects with systolic blood pressure of only $140 \mathrm{mmHg}$ or higher but a diastolic blood pressure of $<90 \mathrm{mmHg}$ were diagnosed as having isolated systolic hypertension. Normal weight, overweight and obesity were defined as a body mass index (BMI) $<24,24-28$, and $>28$ $\mathrm{kg} / \mathrm{m}^{2}$; respectively [32].

\section{Statistical analyses}

The statistical analyses were carried out using the statistical software package SPSS 13.0 (SPSS Inc., Chicago, Illinois). The standard goodness-of-fit test was used to test the Hardy-Weinberg equilibrium. A chi-square analysis was used to evaluate the difference in genotype distribution and sex ratio between the groups. The general characteristics between patients and controls were tested by the Student's unpaired $t$-test. The association of genotypes and serum lipid parameters was tested by analysis of covariance (ANCOVA). Sex, age, BMI, blood pressure, alcohol consumption, cigarette smoking were adjusted for the statistical analysis. Odds ratio (OR) and 95\% confidence interval $(\mathrm{CI})$ were calculated using unconditional logistic regression. Meta-analyses were performed using STATA version 12.0 (Stata Corporation, College Station, Texas, USA). A two-tailed $P$ value less than 0.05 was considered statistically significant.

\section{Results}

\section{General characteristics and serum lipid levels}

The baseline characteristics of the patients and controls are shown in Table 1 . The mean age, ratio of males to females, serum LDL-C and ApoB levels, and the percentages of subjects who smoked cigarette were not different between controls and CAD or IS patients $(P>0.05$ for all). Compared with the control group, the CAD patients had higher levels of average BMI, pulse pressure and serum TG, and lower levels of diastolic blood pressure, serum TC, HDL-C, ApoAI, ApoAI/ApoB, and the percentages of subjects who consumed alcohol $(P<0.05-0.001)$. The IS patients had higher levels of average BMI, systolic blood pressure, diastolic blood pressure, pulse pressure and serum TG, and lower levels of serum TC, HDL-C, ApoAI, ApoAI/ApoB, and the percentages of subjects who consumed alcohol $(\mathrm{P}<0.05-0.001)$.

\section{Genotypic and allelic frequencies}

The genotypic and allelic frequencies of SCARB1 rs5888 SNP are presented in Table 2. The genotype distribution was concordant with the Hardy-Weinberg proportions in both patients and controls $(P=0.114$ for CAD, $P=0.339$ for IS, and $P=0.210$ for controls). There was significant difference in the genotypic frequencies between controls and CAD patients $(P<0.05)$, but not between controls and IS patients $(P>0.05)$.

\section{SCARB I rs5888 SNP and the risk of CAD and IS}

The subjects with TT genotype were associated with increased risk of $\mathrm{CAD}(\mathrm{OR}=1.76,95 \% \mathrm{CI}=$ 1.03-3.01 for TT vs. CC; OR $=1.75,95 \% \mathrm{CI}=1.04-2.95$ for TT vs. CC/CT). There was no significant association between genotypes and the risk of IS (Table 2).

Table I. General characteristics and serum lipid levels between the controls and patients

\begin{tabular}{llll}
\hline Parameter & Control & CAD & IS \\
\hline Number & 582 & 601 & 533 \\
Male/female & $425 / 157$ & $444 / 157$ & $383 / 150$ \\
Age, years & $61.48 \pm 10.85$ & $62.27 \pm 10.55$ & $62.79 \pm 12.27$ \\
Body mass index, $\mathrm{kg} / \mathrm{m}^{2}$ & $22.42 \pm 2.88$ & $24.00 \pm 3.24^{* *}$ & $23.34 \pm 3.48^{* *}$ \\
Systolic blood pressure, $\mathrm{mmHg}$ & $130.89 \pm 19.91$ & $133.22 \pm 23.41$ & $147.85 \pm 22.07^{* *}$ \\
Diastolic blood pressure, $\mathrm{mmHg}$ & $82.19 \pm 12.57$ & $79.27 \pm 14.17^{* *}$ & $84.01 \pm 12.74^{*}$ \\
Pulse pressure, mmHg & $49.50 \pm 14.67$ & $53.50 \pm 18.25^{* *}$ & $63.67 \pm 17.83^{* *}$ \\
Cigarette smoking, $n$ (\%) & $259(44.5)$ & $282(46.9)$ & $214(40.2)$ \\
Alcohol consumption, $n$ (\%) & $263(45.2)$ & $166(27.6)^{* *}$ & $158(29.6)^{* *}$ \\
Total cholesterol, mmol/L & $4.93 \pm 1.09$ & $4.55 \pm 1.22^{* *}$ & $4.52 \pm 1.15^{* *}$ \\
Triglyceride, mmol/L & $1.40 \pm 1.76$ & $1.66 \pm 1.12^{* *}$ & $1.68 \pm 1.40^{* *}$ \\
HDL-C, mmol/L & $1.90 \pm 0.50$ & $1.15 \pm 0.34^{* *}$ & $1.23 \pm 0.41^{* *}$ \\
LDL-C, mmol/L & $2.75 \pm 0.80$ & $2.72 \pm 1.03$ & $2.67 \pm 0.90$ \\
Apolipoprotein (Apo) AI, g/L & $1.41 \pm 0.26$ & $1.04 \pm 0.54^{* *}$ & $1.03 \pm 0.26$ \\
ApoB, g/L & $0.90 \pm 0.22$ & $0.91 \pm 0.27$ & $0.89 \pm 0.25$ \\
ApoAI/ApoB & $1.66 \pm 0.51$ & $1.24 \pm 0.0 .81^{* *}$ & $1.20 \pm 0.61^{* *}$
\end{tabular}

CAD, coronary artery disease; IS, ischemic stroke; HDL-C, high-density lipoprotein cholesterol; LDL-C, low-density lipoprotein cholesterol.

${ }^{*} P<0.05$ and ${ }^{*} P<0.01$, compared with control 
Table 2. Genotypic and allelic frequencies, and the risk for CAD and IS

\begin{tabular}{|c|c|c|c|c|c|c|c|}
\hline \multirow[t]{2}{*}{$\begin{array}{l}\text { Genotype/ } \\
\text { allele }\end{array}$} & $\begin{array}{l}\text { Control, } \\
n(\%)\end{array}$ & $\begin{array}{l}\text { CAD, } \\
n(\%)\end{array}$ & $\begin{array}{l}\text { IS , } \\
\mathrm{n}(\%)\end{array}$ & CAD & & IS & \\
\hline & $n=582$ & $n=601$ & $n=533$ & OR $(95 \% \mathrm{CI})$ & $P$ & OR $(95 \% \mathrm{CI})$ & $P$ \\
\hline$\overline{C C}$ & 324 (55.7) & $324(53.9)$ & $290(54.4)$ & 1 & & 1 & \\
\hline $\mathrm{CT}$ & 228 (39.2) & 224 (37.3) & $212(39.8)$ & $1.02(0.77-1.34)$ & 0.913 & $1.04(0.79-1.38)$ & 0.760 \\
\hline $\mathrm{TT}$ & $30(5.2)$ & $53(8.8)$ & $31(5.8)$ & $1.76(1.03-3.01)$ & 0.038 & $1.25(0.69-2.26)$ & 0.465 \\
\hline$x^{2}$ & & 6.105 & 0.328 & & & & \\
\hline$P$ & & 0.047 & 0.849 & & & & \\
\hline $\mathrm{CC}$ & 324 (55.7) & $324(53.9)$ & $290(54.4)$ & 1 & & 1 & \\
\hline $\mathrm{CT} / \mathrm{TT}$ & 258 (44.3) & $277(46.1)$ & $243(45.6)$ & $1.10(0.85-1.43)$ & 0.461 & $1.07(0.82-1.40)$ & 0.634 \\
\hline$x^{2}$ & & 0.370 & 0.179 & & & & \\
\hline$P$ & & 0.543 & 0.672 & & & & \\
\hline $\mathrm{CC} / \mathrm{CT}$ & $552(94.8)$ & $548(91.2)$ & $502(94.2)$ & 1 & & 1 & \\
\hline TT & $30(5.2)$ & $53(8.8)$ & $31(5.8)$ & 1.75 (1.04-2.95) & 0.036 & $1.23(0.68-2.19)$ & 0.495 \\
\hline$x^{2}$ & & 6.084 & 0.235 & & & & \\
\hline$P$ & & 0.014 & 0.628 & & & & \\
\hline C & 876 (75.3) & $872(72.5)$ & $792(74.3)$ & 1 & & & \\
\hline $\mathrm{T}$ & $288(24.7)$ & $330(27.5)$ & $274(25.7)$ & $1.15(0.96-1.38)$ & 0.133 & $1.05(0.87-1.27)$ & 0.601 \\
\hline$x^{2}$ & & 2.254 & 0.273 & & & & \\
\hline$P$ & & 0.133 & 0.601 & & & & \\
\hline
\end{tabular}

CAD, coronary artery disease; IS, ischemic stroke.

\section{Genotypes and serum lipid levels}

As shown in Table 3 and 4, the subjects with TT genotype in the total population had lower serum HDL-C levels than those with CT/CC genotypes $(P=$ 0.049). The subjects with TT genotype in controls but not in CAD or IS patients had higher levels of serum LDL-C and ApoB than those with CC genotype $(P<$ 0.05; Table 4).

\section{Meta-analysis of the previous association studies}

Previous association studies between the SCARB1 rs5888 SNP and atherosclerosis related diseases are presented in Table 5. We performed a meta-analysis including three studies which had detailed the genotype frequencies. The pooled OR and $95 \% \mathrm{CI}$ were $0.737(0.591-0.918)$ for TT vs. CC+CT $(P=0.007)$, and $0.902(0.764-1.064)$ for $\mathrm{CT}+\mathrm{TT}$ vs. CC $(P=0.222)$, and $0.919(0.828-1.019)$ for $\mathrm{T}$ allele vs. $\mathrm{C}$ allele $(P=$ $0.108)$.

\section{Discussion}

The results of several previous association studies between the SCARB1 rs5888 SNP and atherosclerosis related diseases are not entirely consistent in different ethnic groups (Table 5). Ritsch et al. [26] showed that the T allele of rs5888 SNP was associated with decreased risk of peripheral arterial disease in Austrians. The T allele carriers of the SCARB1 rs5888 SNP in Tunisan reduced the risk of coronary stenosis and increased serum HDL-C levels [27]. Recently, the TT genotype of the SCARB1 rs5888 SNP in male Lithuanian aged 65-75 was also shown to decrease the risk of CAD and increase serum HDL-C levels [28]. Two other studies in Korean and Spanish [24,25] did not report the genotype frequencies, but they also showed that the $\mathrm{T}$ allele or the $\mathrm{T}$ allele carrier was associated with decreased CAD risk. In the present study, however, we showed that the frequency of TT genotype was higher in CAD patients than in controls. The TT genotype was associated with increased risk of CAD than the CC or CC/CT genotype. The TT genotype was also associated with decreased serum HDL-C levels in the total population. Meta-analysis including three previous association studies showed that the TT genotype was associated with decreased risk of CAD. The reasons for the conflicting results between our and previous studies are not well known. One of the possible explanations was different genetic background. According to the data of the International HapMap project, the allelic frequencies of the SCARB1 rs5888 SNP in diverse racial/ethnic groups are different. The frequencies of $\mathrm{C}$ and $\mathrm{T}$ alleles were $47.4 \%$ and $52.6 \%$ in CEU (Utah residents with ancestry from northern and western Europe), $88.1 \%$ and $11.9 \%$ in YRI (Yoruba in Ibadan, Nigeria), $80.7 \%$ and $19.3 \%$ in JPT (Japanese in Tokyo, Japan), $75.6 \%$ and $24.4 \%$ in CHB (Han Chinese in Beijing, China). In addition, the C-T change at exon 8 did not affect its amino acid sequence of the protein. Therefore, the rs5888 SNP might be in linkage disequilibrium (LD) with a functional mutation in the SCARB1 gene, and the LD pattern at this region is different among populations. Accordingly, it is necessary to further study on the associations of the SCARB1 rs5888 SNP and atherosclerosis related diseases in different ethnic populations. 
Table 3. Effect of the genotypes on serum lipid levels in the combined population

\begin{tabular}{llllllll}
\hline Genotype & $\begin{array}{l}\mathrm{TC}, \\
\mathrm{mmol} / \mathrm{L}\end{array}$ & $\begin{array}{l}\text { TG, } \\
\mathrm{mmol} / \mathrm{L}\end{array}$ & $\begin{array}{l}\text { HDL-C, } \\
\mathrm{mmol} / \mathrm{L}\end{array}$ & $\begin{array}{l}\text { LDL-C, } \\
\mathrm{mmol} / \mathrm{L}\end{array}$ & $\begin{array}{l}\text { ApoAI, } \\
\mathrm{g} / \mathrm{L}\end{array}$ & $\begin{array}{l}\text { ApoB, } \\
\mathrm{g} / \mathrm{L}\end{array}$ & $\begin{array}{l}\text { ApoAI/ } \\
\text { ApoB }\end{array}$ \\
\hline $\mathrm{CC}, n=938$ & $4.66 \pm 1.13$ & $1.59 \pm 1.37$ & $1.44 \pm 0.57$ & $2.71 \pm 0.91$ & $1.17 \pm 0.45$ & $0.89 \pm 0.24$ & $1.40 \pm 0.78$ \\
$\mathrm{CT}, n=664$ & $4.67 \pm 1.22$ & $1.55 \pm 1.62$ & $1.44 \pm 0.52$ & $2.72 \pm 0.93$ & $1.16 \pm 0.35$ & $0.91 \pm 0.25$ \\
$\mathrm{TT}, n=114$ & $4.71 \pm 1.20$ & $1.58 \pm 1.12$ & $1.34 \pm 0.47$ & $2.69 \pm 0.90$ & $1.16 \pm 0.45$ & $0.90 \pm 0.24$ & $1.35 \pm 0.55$ \\
$P$ & 0.909 & 0.856 & 0.143 & 0.931 & 0.969 & 0.498 & 0.304 \\
$\mathrm{CC} / \mathrm{CT}, n=1602$ & $4.67 \pm 1.17$ & $1.58 \pm 1.48$ & $1.44 \pm 0.55$ & $2.72 \pm 0.92$ & $1.16 \pm 0.41$ & $0.90 \pm 0.25$ & $1.37 \pm 0.69$ \\
$\mathrm{TT}, n=114$ & $4.71 \pm 1.20$ & $1.58 \pm 1.12$ & $1.34 \pm 0.47$ & $2.69 \pm 0.90$ & $1.16 \pm 0.45$ & $0.90 \pm 0.24$ & $1.34 \pm 0.63$ \\
$P$ & 0.680 & 0.950 & 0.049 & 0.794 & 0.928 & 0.942 & 0.563 \\
\hline
\end{tabular}

TC, total cholesterol; TG, triglyceride; HDL-C, high-density lipoprotein cholesterol; LDL-C, low-density lipoprotein cholesterol; ApoAI, apolipoprotein AI; ApoB, apolipoprotein B.

Table 4. Effect of the genotypes on serum LDL-C and ApoB levels in the controls and patients

\begin{tabular}{|c|c|c|c|c|c|c|}
\hline \multirow[t]{2}{*}{ Genotype } & \multicolumn{2}{|l|}{ Control } & \multicolumn{2}{|l|}{ CAD } & \multicolumn{2}{|l|}{ IS } \\
\hline & \multicolumn{2}{|c|}{ LDL-C, mmol/L ApoB, g/L } & \multicolumn{2}{|c|}{ LDL-C, mmol/L ApoB, g/L } & \multicolumn{2}{|c|}{ LDL-C, mmol/L ApoB, g/L } \\
\hline$\overline{C C}$ & $2.70 \pm 0.82$ & $0.88 \pm 0.22$ & $2.69 \pm 0.98$ & $0.88 \pm 0.26$ & $2.73 \pm 0.92$ & $0.91 \pm 0.25$ \\
\hline $\mathrm{CT}$ & $2.76 \pm 0.77$ & $0.92 \pm 0.21$ & $2.78 \pm 1.11$ & $0.94 \pm 0.28$ & $2.62 \pm 0.86$ & $0.87 \pm 0.24$ \\
\hline TT & $3.11 \pm 0.80$ & $0.93 \pm 0.21$ & $2.49 \pm 1.03$ & $0.88 \pm 0.28$ & $2.69 \pm 0.92$ & $0.90 \pm 0.21$ \\
\hline$P$ & 0.023 & 0.040 & 0.165 & 0.074 & 0.457 & 0.159 \\
\hline $\mathrm{CC} / \mathrm{CT}$ & $2.73 \pm 0.80$ & $0.89 \pm 0.22$ & $2.73 \pm 1.04$ & $0.91 \pm 0.27$ & $2.68 \pm 0.90$ & $0.90 \pm 0.25$ \\
\hline TT & $3.11 \pm 0.80$ & $0.93 \pm 0.21$ & $2.49 \pm 0.90$ & $0.88 \pm 0.28$ & $2.69 \pm 0.92$ & $0.90 \pm 0.21$ \\
\hline$P$ & 0.012 & 0.374 & 0.115 & 0.496 & 0.957 & 0.995 \\
\hline
\end{tabular}

LDL-C, low-density lipoprotein cholesterol; ApoB, apolipoprotein B.

Table 5. Previous association studies between the SCARB/ rs5888 SNP and atherosclerosis related diseases

\begin{tabular}{|c|c|c|c|c|c|c|c|}
\hline $\begin{array}{l}\text { Ethnic/ } \\
\text { nation }\end{array}$ & Locus & $\begin{array}{l}\text { Patient/ } \\
\text { control }\end{array}$ & lipid & Disease & $\mathrm{CC} / \mathrm{CT} / \mathrm{TT}$ & Risk & Reference \\
\hline Austrians & C1050T & $354 / 354$ & $\begin{array}{l}\text { TC, LDL (combined genotype ex- } \\
\text { on1/intron5/exon } 8 \text { ) }\end{array}$ & $\begin{array}{l}\text { Peripheral arterial dis- } \\
\text { ease }\end{array}$ & $\begin{array}{l}107 / 188 / 59 \\
101 / 170 / 83\end{array}$ & $\begin{array}{l}\mathrm{T} \downarrow \text { (in } \\
\text { females) }\end{array}$ & [26] \\
\hline Spanish & $\mathrm{C} 1050 \mathrm{~T}$ & $304 / 315$ & $\begin{array}{l}\text { Scarb1 expression } \uparrow \text {, Cholesteryl ester } \\
\text { hydroperoxides } \uparrow\end{array}$ & Coronary heart disease & No description & $\mathrm{T} \downarrow$ & [25] \\
\hline Korean & $\mathrm{C} 1050 \mathrm{~T}$ & $137 / 124$ & HDL-C and ApoAI $\uparrow$ in patients & Coronary artery disease & No description & $\mathrm{T} \downarrow$ & {$[24]$} \\
\hline Tunisian & $\mathrm{C} 1050 \mathrm{~T}$ & $212 / 104$ & HDL-C $\uparrow$, ApoAI $\uparrow$ & Coronary artery stenosis & $\begin{array}{l}105 / 96 / 11 \\
34 / 58 / 11\end{array}$ & $\mathrm{~T} \downarrow$ & [27] \\
\hline Lithuanian & $\mathrm{C} 1050 \mathrm{~T}$ & $468 / 1976$ & $\begin{array}{l}\text { TT genotype:TC, TG, } \mathrm{LDL}-\mathrm{C} \uparrow \text { in male, } \\
\text { HDL-C } \uparrow \text { in male age } 65-74 \text { years }\end{array}$ & Myocardial infarction & $\begin{array}{l}163 / 233 / 67 \\
696 / 944 / 336\end{array}$ & $\begin{array}{l}\mathrm{TT} \downarrow \text { (male } \\
65-74 \text { years) }\end{array}$ & [28] \\
\hline
\end{tabular}

TC, total cholesterol; TG, triglyceride; HDL-C, high-density lipoprotein cholesterol; LDL-C, low-density lipoprotein cholesterol; ApoAI, apolipoprotein AI; $\uparrow$, increase; $\downarrow$, decrease

The association between SCARB1 rs5888 SNP and serum lipid levels has been described in other several previous studies, which were recently summarized by Stanislovaitiene et al. [28], and also discussed in our recent reports $[29,30]$. Some studies showed that the SCARB1 rs5888 SNP T allele was associated with increased serum HDL-C levels $[16,18,20,24,27,28]$ and decreased serum non-HDL-C concentrations $[17,20]$, and therefore has an atheroprotective effect. But other studies found that this SNP $\mathrm{T}$ allele has a pro-atherosclerosis serum lipid profile. Tai et al. [23] showed that the exon 8 (rs5888) SNP was associated with increased TC, very-low-density lipoprotein cholesterol (VLDL-C), LDL-C and TG levels in subjects with heterozygous familial hypercholesterolemia. Morabia et al. [18] reported that the subjects with TT genotype had higher levels of TC and LDL-C than the subjects with CC genotype in females. Stanislovaitiene et al. [28] also found that the TT genotype was associated with increased serum TC, TG and LDL-C levels in males. In our previous studies, we observed that the TT genotype was associated with low serum HDL-C and ApoAI levels in the Guangxi Bai Ku Yao, Mulao and Han populations $[29,30]$, and the T allele was associated with increased serum TC, LDL-C, and ApoB levels in Bai $\mathrm{Ku}$ Yao females, and increased serum TG and ApoB levels in Han males. In the present study, we showed that the TT genotype was also associated with increased serum LDL-C and ApoB levels in con- 
trols.

The relationship between the SCARB1 gene and serum lipid levels and atherosclerosis is complex and inconsistent. Mice with attenuated expression of SCARB1 displays elevated concentrations of HDL-C [11]. A study in women with hyperalphalipoproteinemia also showed that the SCARB1 protein was inversely correlated with HDL-C levels and HDL size [12]. A 11-base pair deletion mutation in the promoter region of the $S C A R B 1$ gene was associated with increased plasma HDL-C levels in Chinese Taiwanese [21], which was consistent with several previous studies $[16,18,20,24,27,28]$. However, the results of previous association studies between the SCARB1 rs5888 SNP and atherosclerosis related diseases in human were opposite with those in animal models. $S R-B I$ knockout mice in the background of either ApoE or LDL receptor deficiency have been shown to accelerate atherosclerosis and increase LDL-C without significant alterations in HDL-C levels, suggesting that impaired LDL-C clearance may account for the increased atherosclerosis relative to these mice $[14,15]$. In addition, the SCARB1 rs5888 SNP was also associated with reduced $S C A R B 1$ protein expression and function in vitro [33]. Therefore, the possible mechanism of association between TT genotype of SCARB1 rs5888 SNP and increased risk of CAD may be related to the reduction in $S C A R B 1$ protein expression resulting the increase in serum LDL-C and ApoB levels.

\section{Study limitations}

There are several potential limitations of the present study. Firstly, the drug information was missing in some participants, so interference by drug therapy could not be analyzed or excluded. Secondly, the sample size of our study, especially the number of the subjects with TT genotype was a bit small, which might not have sufficient power to interpret the associations of the rs5888 SNP and the risk of diseases. Therefore large study population with sufficient power required to duplicate these results.

\section{Conclusion}

The present study shows that the TT genotype of SCARB1 rs5888 SNP was higher in CAD patients than in controls; the TT genotype was associated with increased risk of CAD. The levels of serum HDL-C in subjects with TT genotype was lower than those in subjects with CC/CT genotype in the total population, the subjects with TT genotype also associated with increased serum levels of LDL-C and ApoB than those with CC/CT genotype in controls. These suggest that the SCARB1 rs5888 SNP influences serum lipid levels, and is associated with the risk of CAD.

\section{Acknowledgments}

This study was supported by the National Natural Science Foundation of China (No: 30960130), the Science Foundation of Guangxi Returned Oversea Scholars (No: 0991004) and the Innovation Project of Guangxi Graduate Education (No: YCBZ2013013).

\section{Competing Interests}

The authors have declared that no competing interest exists.

\section{References}

1. Murray CJ, Vos T, Lozano R, et al. Disability-adjusted life years (DALYs) for 291 diseases and injuries in 21 regions, 1990-2010: a systematic analysis for the Global Burden of Disease Study 2010. Lancet. 2012; 380:2197-223.

2. Fruchart JC, Nierman MC, Stroes ES, et al. New risk factors for atherosclerosis and patient risk assessment. Circulation. 2004; 109:III15-9.

3. Pasternak RC, Criqui MH, Benjamin EJ, et al. Atherosclerotic Vascular Disease Conference: Writing Group I: epidemiology. Circulation. 2004; 109:2605-12

4. Castelli WP, Garrison RJ, Wilson PW, et al. Incidence of coronary heart disease and lipoprotein cholesterol levels. The Framingham Study. JAMA. 1986; 256:2835-8.

5. Gordon DJ, Probstfield JL, Garrison RJ, et al. High-density lipoprotein cholesterol and cardiovascular disease. Four prospective American studies. Circulation. 1989; 79:8-15.

6. Tanne D, Yaari S, Goldbourt U. High-density lipoprotein cholesterol and risk of ischemic stroke mortality.A 21-year follow-up of 8586 men from the Iraeli Ischemic Heart Disease Study. Stroke. 1997; 28:83-7.

7. Soyama Y, Miura K, Morikawa Y, et al. High-density lipoprotein cholesterol and risk of stroke in Japanese men and women: the Oyabe Study. Stroke. 2003; 34:863-8.

8. Yin $\mathrm{RX}, \mathrm{Li} Y \mathrm{Y}, \mathrm{Wu} \mathrm{JZ}$, et al. Interactions between the apolipoprotein a1/c3/a5 haplotypes and alcohol consumption on serum lipid levels. Alcohol Clin Exp Res. 2013; 37:234-43.

9. Yin $\mathrm{RX}, \mathrm{Wu} \mathrm{DF}, \mathrm{Wu} \mathrm{JZ}$, et al. Interactions of several lipid-related gene polymorphisms and cigarette smoking on blood pressure levels. Int J Biol Sci. 2012; 8:685-96.

10. Acton S, Rigotti A, Landschulz KT, et al. Identification of scavenger receptor SR-BI as a high density lipoprotein receptor. Science. 1996; 271:518-20.

11. Rigotti A, Trigatti BL, Penman M, et al. A targeted mutation in the murine gene encoding the high density lipoprotein (HDL) receptor scavenger receptor class B type I reveals its key role in HDL metabolism. Proc Natl Acad Sci USA. 1997; 94:12610-12615

12. West M, Greason E, Kolmakova A, et al. Scavenger receptor class B type I protein as an independent predictor of high-density lipoprotein cholesterol levels in subjects with hyperalphalipoproteinemia. J Clin Endocrinol Metab. 2009; 94:1451-57.

13. Ueda Y, Royer L, Gong E, et al. Lower plasma levels and accelerated clearance of high density lipoprotein (HDL) and non-HDL cholesterol in scavenger receptor class B type I transgenic mice. J Biol Chem. 1999; 274:7165-71.

14. Huszar D, Varban ML, Rinninger F, et al. Increased LDL cholesterol and atherosclerosis in LDL receptor-deficient mice with attenuated expression of scavenger receptor B1. Arterioscler Thromb Vasc Biol. 2000; 20:1068-73.

15. Covey SD, Krieger M, Wang W, et al. Scavenger receptor class B type I-mediated protection against atherosclerosis in LDL receptor-negative mice involves its expression in bone marrow-derived cells. Arterioscler Thromb Vasc Biol. 2003; 23:1589-94.

16. Roberts CG, Shen H, Mitchell BD, et al. Variants in scavenger receptor class B type I gene are associated with HDL cholesterol levels in younger women. Hum Hered. 2007; 64:107-13.

17. Acton S, Osgood D, Donoghue M, et al. Association of polymorphisms at the SR-BI gene locus with plasma lipid levels and body mass index in a white population. Arterioscler Thromb Vasc Biol. 1999; 19:1734-43.

18. Morabia A, Ross BM, Costanza MC, et al. Population-based study of SR-BI genetic variation and lipid profile. Atherosclerosis. 2004; 175:159-68.

19. McCarthy JJ, Lewitzky S, Reeves C, et al. Polymorphisms of the HDL receptor gene associated with HDL cholesterol levels in diabetic kindred from three populations. Hum Hered. 2003; 55:163-70.

20. Osgood D, Corella D, Demissie S, et al. Genetic variation at the scavenger receptor class B type I gene locus determines plasma lipoprotein concentrations and particle size and interacts with type 2 diabetes: the framingham study. J Clin Endocrinol Metab. 2003; 88:2869-79.

21. Hsu LA, Ko YL, Wu S, et al. Association between a novel 11-base pair deletion mutation in the promoter region of the scavenger receptor class B type I gene and plasma HDL cholesterol levels in Taiwanese Chinese. Arterioscler Thromb Vasc Biol. 2003; 23:1869-74. 
22. McCarthy JJ, Lehner T, Reeves C, et al. Association of genetic variants in the HDL receptor, SR-B1, with abnormal lipids in women with coronary artery disease. J Med Genet. 2003; 40:453-8

23. Tai ES, Adiconis X, Ordovas JM, et al. Polymorphisms at the SRBI locus are associated with lipoprotein levels in subjects with heterozygous familial hypercholesterolemia. Clin Genet. 2003; 63:53-8.

24. Hong SH, Kim YR, Yoon YM, et al. Association between HaeIII polymorphism of scavenger receptor class $B$ type I gene and plasma HDL-cholesterol concentration. Ann Clin Biochem. 2002; 39:478-81.

25. Rodríguez-Esparragón F, Rodríguez-Pérez JC, Hernández-Trujillo Y, et al. Allelic variants of the human scavenger receptor class $B$ type 1 and paraoxonase 1 on coronary heart disease: genotype-phenotype correlations. Arterioscler Thromb Vasc Biol. 2005; 25:854-60.

26. Ritsch A, Sonderegger G, Sandhofer A, et al. Scavenger receptor class B type I polymorphisms and peripheral arterial disease. Metabolism. 2007; 56:1135-41.

27. Rejeb J, Omezzine A, Boumaiza I, et al. Association of three polymorphisms of scavenger receptor class BI gene (exon8, exon1, intron5) with coronary stenosis in a coronary Tunisian population. Gene. 2012; 511:383-8.

28. Stanislovaitiene D, Lesauskaite V, Zaliuniene D, et al. SCARB1 single nucleotide polymorphism (rs5888) is associated with serum lipid profile and myocardial infarction in an age- and gender-dependent manner. Lipids Health Dis. 2013; 12:24.

29. Wu DF, Yin RX, Hu XJ, et al. Association of rs5888 SNP in the scavenger receptor class B type 1 gene and serum lipid levels. Lipids Health Dis. 2012; 11:50.

30. Wu DF, Yin RX, Yan TT, et al. The SCARB1 rs5888 SNP and serum lipid levels in the Guangxi Mulao and Han populations. Int J Med Sci. 2012; 9:715-24.

31. Chalmers J, MacMahon S, Mancia G, et al. 1999 World Health Organization-International Society of Hypertension Guidelines for the management of hypertension. Guidelines sub-committee of the World Health Organization. Clin Exp Hypertens. 1999; 21:1009-60.

32. Zhou BF. Effect of body mass index on all-cause mortality and incidence of cardiovas-cular diseases - report for meta-analysis of prospective studies open optimal cut-off points of body mass index in Chinese adults. Biomed Environ Sci. $2002 ; 15: 245-52$.

33. Constantineau J, Greason E, West M, et al. A synonymous variant in scavenger receptor, class B, type I gene is associated with lower SR-BI protein expression and function. Atherosclerosis. 2010; 210:177-82 